\title{
Kültürel Mirasın Fotogrametrik Yöntemle 3B Modellenmesi: Karabıyık Köprüsü Örneği
}

\author{
Alperen Erdoğan*1® ${ }^{*}$, Adem Kabadayı ${ }^{1 \oplus}$, Emine Saka Akın²® \\ ${ }_{1}$ Yozgat Bozok Üniversitesi, Şefaatli MYO, Mimarlık Şehir Planlama Bölümü, Yozgat, Türkiye \\ ${ }^{2}$ Yozgat Bozok Üniversitesi, Mühendislik ve Mimarlık Fakültesi, Mimarlık Bölümü, Yozgat, Türkiye
}

\author{
Anahtar Kelimeler \\ İHA \\ Kültürel Miras \\ Fotogrametri \\ Rölöve \\ Karabıyık Köprüsü
}

\begin{abstract}
ÖZ
İnsanlığın varoluşundan günümüze kadar bütün uygarlıklar yaşadıkları devirlerin sosyal, ekonomik ve kültürel özelliklerini inşa ettikleri tüm yapılarda barındırmışlardır. Kültürel miras olarak nitelendirilen bu yapıların korunması, yaşatılması ve gelecek nesillere sağlıklı bir şekilde aktarılması günümüzün önemli koruma sorunlarından birisidir. Dünyada olduğu gibi Türkiye'de de kültürel mirasın korunmasına yönelik yapılacak çalışmalarda ilk adım yapıya zarar vermeden rölövelerinin çlkarılarak belgelenmesidir. Günümüzde teknolojik gelişmelere paralel olarak rölöve teknikleri de gelişmiștir. Son yıllarda fotogrametrik yazılım ve donanımlardaki gelişmeler sayesinde fotogrametrik rölöve çalışmaları daha hızlı, daha hassas ve daha ekonomik olarak yapılabilmekte ve 3B dijital modelleri oluşturulmaktadır. Bu çalışmada da Yozgat ilinde bulunan ve Osmanlı Dönemi'nde Yavuz Sultan Selim'in 1516 yılında Mısır seferi sırasında yaptırmış olduğu Karabıyık Köprüsü'nün fotogrametrik yöntemle 3B modellemesi yapılmıştır. Fotogrametrik rölöve çalışmaları sırasında dünya yüzeyindeki objelerin 3B modellenmesine izin veren İnsansız Hava Aracı da (İHA) kullanılmıştır. İHA'lardan elde edilen görüntüler ile Pix4D yazılımı kullanılarak 3B nokta bulutu üretilmiştir. Bu çalışmada yürütülen fotogrametri yöntemi ile daha hızlı, hassas, güvenli ve ekonomik bir şekilde veriler elde edilmiştir. Sonuç olarak fotogrametrik yöntemle 3B modelleri elde edilen tarihi ve kültürel değerler ile restorasyon projelerinin altlıklarının daha sağlıklı olmalarına olanak verecektir.
\end{abstract}

\section{D Modeling of Cultural Heritage with Photogrammetric Method: The Case of Karabıyık Bridge}

Keywords

UAV

Cultural Heritage

Photogrammetry

Surveying

Karabiyik Bridge

\begin{abstract}
From the existence of humanity to the present, all civilizations have harbored the social, economic and cultural characteristics of their eras in all the structures they built. Preserving, preserving and transferring these structures, which are described as cultural heritage, to future generations in a healthy way is one of the important conservation problems of today. In Turkey, as in the world in the work to be done for the protection of cultural heritage is documented by subtracting the first step in building surveys without damaging the structure. Today, surveying techniques have also developed in parallel with technological developments. Thanks to the developments in photogrammetric software and hardware in recent years, photogrammetric survey studies can be done faster, more precisely and more economically and 3D digital models are created. In this study, 3D modeling of the Karabiyık Bridge, which was built by Yavuz Sultan Selim during the Egyptian expedition in 1516 in the city of Yozgat, was made by photogrammetric method. Unmanned Aerial Vehicle (UAV), which allows 3D modeling of objects on earth surfaces, was also used during photogrammetric survey studies. 3D point cloud was produced using Pix4D software with images obtained from UAVs. With the photogrammetry method carried out in this study, data were obtained in a faster, more precise, safe and economical way. As a result, the data obtained by 3D modeling with photogrammetric method will allow the bases of the restoration projects of historical and cultural values to be healthier.
\end{abstract}




\section{Gíriş}

Kültürel miraslar yapı stoku olarak ekonomik bir işleve sahip olmalarının yanı sıra toplumsal olarak tarihi ve kültürel ișlevleri (Tanyeli, 1979) ile geçmișle gelecek arasında kurulacak bağda en önemli köprülerden biridir.

Kültürel mirasların günümüze gelene kadar bozulmalarına neden olan pek çok iç ve dış etken bulunmaktadır (Yiğit \& Ulvi, 2020; Kaya vd., 2021) Bu eserle; yapının bulunduğu zemin, malzeme gibi etkenlerden insanların ihmal-tahrip etmeleri, savaş, deprem, yangın, sel gibi pek çok olumsuz etkenlere maruz kalarak günümüze kadar gelebilmişlerdir (Ahunbay, 2004; Kaya \& Yiğit, 2020; Kabadayı vd., 2020). $\mathrm{Bu}$ nedenle günümüze gelebilen, tekrar üretilemeyecek, geri dönülmesi mümkün olmayan kültürel miras değerlerinin korunmaları için en küçük noktasına kadar tahribatsız bir şekilde belgelenmeleri çok önemlidir (Hamal vd., 2020).

$\mathrm{Bu}$ nedenle belgeleme çalıșmalarında günümüz teknolojilerinden faydalanılarak fotogrametrik rölöve tekniğinin kullanılması giderek önem kazanmaktadır. Çünkü fotogrametri, bir nesnenin 3 boyutlu eksiksiz bir dokümantasyonun oluşturulmasına olanak sağlar ve dolayısıyla herhangi bir eserin dijital olarak arşivlemesini de mümkün kılar.

Fotogrametri, elektromanyetik enerji ve fotografik görüntüleri kaydetmek, ölçme ve yorumlama süreçleri yoluyla fiziksel nesneler ve çevre hakkında güvenilir bilgi elde etme sanatı, bilimi ve teknolojisi olarak tanımlanmaktadır (Aber vd., 2010).

Bir nesnenin geometrisi, rengi ve dokusu hakkında üç boyutlu bilgi toplamayı amaçlayan fotogrametri süreci dijital görüntülerin elde edilmesi ile $3 \mathrm{~B}$ sanal bir modelin oluşturulmasına olanak veren bir tekniktir.

Fotogrametri, son gelişmelerle birlikte İnsansız Hava Araçlarından (İHA) fotoğraf çekme imkânı sunmaktadır. Bu olanak İHA tarafından çekilen fotoğraflar yardımıyla, dünya yüzeyindeki objelerin hızlı ve ekonomik bir şekilde 3B modellenmesine izin vermektedir (Turner vd., 2012; Ulvi vd., 2020). Bu da ulaşılması güç olan en zor noktaya dahi ulaşma imkanı sağlamaktadır.

İHA fotogrametrisi (Eisenbeiss, 2008), uzaktan kumandalı olarak çalışan, yarı bağımsız veya bağımsız olan ve herhangi bir pilotun bulunmadığı bir fotogrametrik ölçüm platformunu tanımlar (Alptekin \& Yakar, 2020a). Platform, fotogrametrik ölçüm sistemleri ile donatılmıştır. Mevcut standart İHA, yerel veya küresel bir koordinat sisteminde uygulanan sensörlerin kaydı ve konumu ile yönünün izlenmesini sağlar (Kaya ve Yiğit, 2020). Dolayısıyla İHA fotogrametrisi, insansız hava aracı yardımıyla fotogrametrik ölçümler yapan bir teknik olarak anlaşlabilir (Ulvi, 2021).

3B model oluşturmada farklı fotogrametrik yaklaşımlar kullanılmaya başlanmıştır (Sarıtürk \& Şeker, 2017). Bu yaklaşımlardan en çok tercih edilen ise Hareket ile Nesne Oluşturma- Structure From Motion (SFM) yöntemi olmuştur (Dellaert vd., 2000; Furukawa \& Hernández, 2013; Sarıtürk \& Şeker, 2017).

Normalde SfM fotogrametrisi ile elde edilen herhangi bir 3B yüzey modeli, başlangıçta rastgele bir referans sisteminde oluşturulur. Coğrafi referans, bu ilk verinin önceden tanımlanmış bir koordinat referans sistemine dönüștürülmesini içerir. $\mathrm{Bu}$, doğrudan fotoğrafların bilinen dış yönelimleri kullanılarak ("doğrudan coğrafi referanslama") veya fotoğraflarda tanınabilen noktalara (yer kontrol noktaları veya GCP) uygun koordinatlar sağlanarak yapılabilir (dolaylı coğrafi referanslama).

Hassas, hızlı ve ekonomik bir şekilde yapılan fotogrametrik rölöve tekniği ile hem yapılara zarar verilmemekte hem de arkeolojik kazı alanları gibi büyük alanlarda insan güvenliğini de sağlayacaktır.

Bu çalışmada kültürel mirasın korunmasına yönelik rölöve çalışmalarında fotografik yöntem kullanılarak Yozgat Karabıyı Köprüsü'nde 3B modelleme yapılmıştır.

\section{KARABIYIK KÖPRÜSÜ}

Osmanlı Dönemi'nden günümüze birçok tarihi eser kalmıştır. Bu eserlerden olan Karabıyık Köprüsü üzerinde yazan kitabesine göre 1516 yılında Yavuz Sultan Selim tarafindan Misır seferi sırasında yaptırılmıştır (Şekil 1).

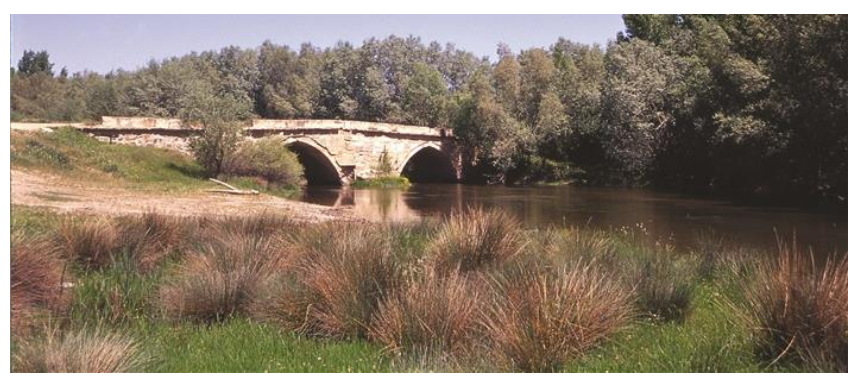

Şekil 1. Karabıyık köprüsü restorasyon öncesi görünüm

Köprünün zamanla yıpranmasından dolayı 2018 yılında aslına uygun olarak restorasyonu yapılmıștır (Şekil 2). Uzunluğu 54 metre olup, 4.51 metrelik bir eni vardır. Kemer açıklıkları ise 6.60 metredir. Yozgat şehrinin en eski yapılarından biridir. Köprü ayakları üzerinde mahmuzlar bulunmaktadır. Ayrıca korkuluk duvarı ile köprü başlangıcındaki baba taşları beyaz kesme taştan yapılmıștır. Restorasyon sonrası köprünün batı kısmına kitabe koyulmuştur.

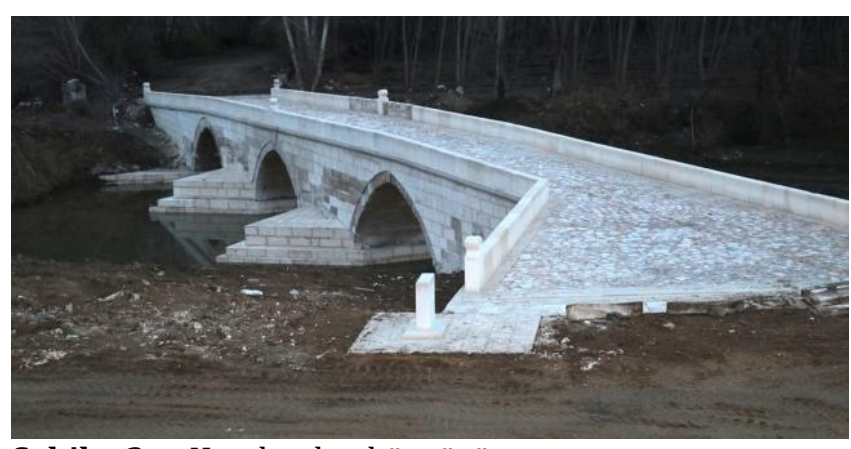

Şekil 2. Karabıyık köprüsü restorasyon sonrası görünüm 


\section{ARAZI ÇALIŞMASI}

Arazi çalışması için belirlenen Karabıyık Köprüsü Yozgat - Kayseri yolu yakınında, Yozgat'a $35 \mathrm{~km}$ uzaklıkta ve Yozgat ilinin güney batısında yer almaktadır (Şekil 3).

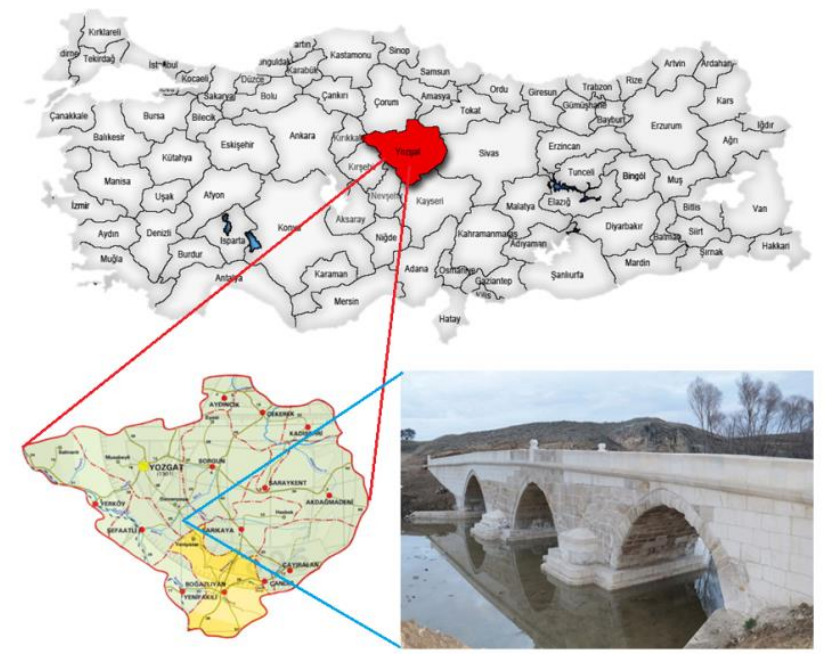

Şekil 3. Karabıyık köprüsü konum bilgisi

Fotogrametrik yöntemle yapılan rölöve çalışmasında ilk olarak arazi çalışması yapılmıştır. Fotogrametrik yöntemle dengelemenin yapılabilmesi için yapı üzerinde koordinatları bilinen yer kontrol noktalarına ihtiyaç olduğundan daha önceden hazırlanan ve resimlerde kolayca seçilebilen numaralanmış $20 \times 30 \mathrm{~cm}$ boyutlarında kâğıt plakalar yapı üzerine yerleştirilmiştir (Şekil 4).

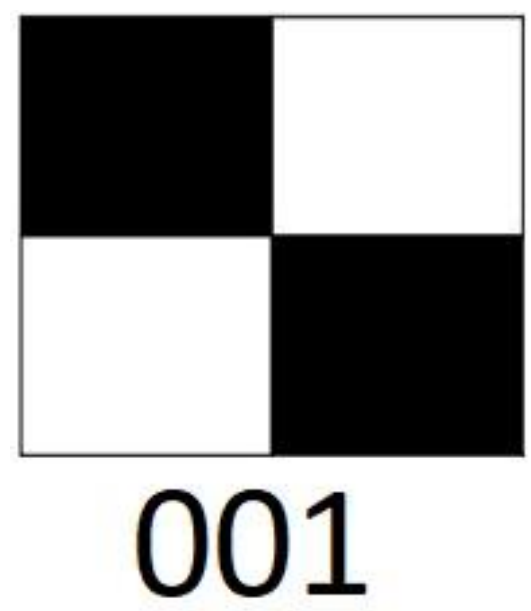

Şekil 4. 20x30 olarak hazırlanan kâğıt plakalar

Obje etrafına poligon noktaları tesis edilerek poligon noktaları GPS kullanılarak ITRF-96 koordinat sisteminde dilim orta meridyeni 36 olacak şekilde temin edilmiştir (Şekil 5). Yapı çevresine ve üzerine homojen dağılımlı olarak 7 adet kâğıt plakalar tesis edilmiştir. Tesis edilen Totalstation jeodezik ölçme aleti yardımıyla yapı üzerine yerleștirilen kâğıt plakaların koordinatları belirlenmiștir (Şekil 6).
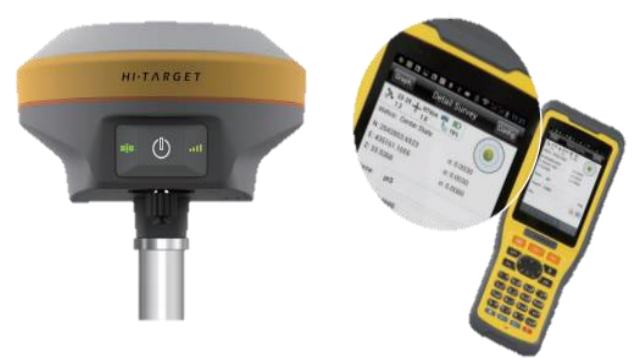

Şekil 5. GPS Cihazı

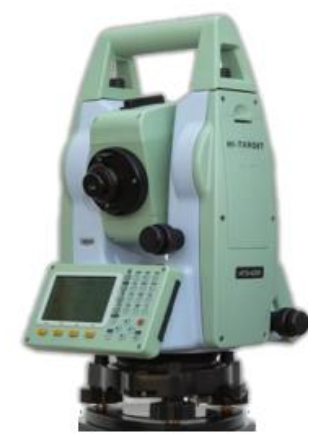

Şekil 6. Totalstation jeodezik ölçme aleti

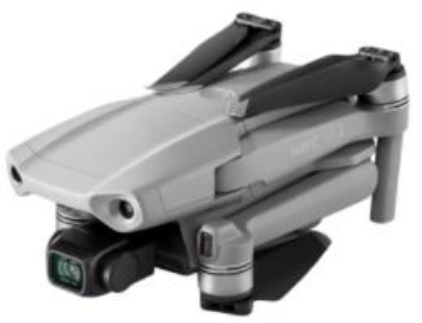

Şekil 7. DJI Mavic Air 2 cihazı

Kâğıt plakalar yapı üzerine yerleștirildikten sonra DJI Mavic Air 2 yardımıyla havadan modelin tüm detaylarını kaplayacak șekilde bindirmeli resimleri çekilmiştir (Şekil 7). Resim çekimleri için kullanılan DJI Mavic Air 2 cihazının özellikleri Tablo 1' sunulmuștur.

Tablo 1. DJI Mavic Air 2 Özellikleri

\begin{tabular}{ll}
\hline Dahili Kamera & Evet \\
Görüş Açısı & $84^{\circ}$ \\
Diyafram Açıklı̆̆ı & $2.8 / \mathrm{f}$. \\
Sensör Boyutu & $1 / 2 \mathrm{inç}$ \\
Etkin Piksel & $48 \mathrm{MP}$. \\
Video Çözünürlüğ̈̈ & $4 \mathrm{~K}$. \\
Video Kare Hızı & $60 \mathrm{fps}$. \\
Fotoğraf çözünürlüğü & $6000 x 8000$ \\
Uçuş süresi & $34 \mathrm{dk}$ \\
\hline
\end{tabular}

Yukarıda teknik özellikleri verilen İHA ile iki saat gibi sürede arazi çalışmaları tamamlanmıştır. Daha sonraki süreç büro çalışmaları olarak devam etmiştir. 


\section{FOTOGRAMETRÍK DEĞERLENDİRME}

SFM, yer bilimlerinde hızla popüler hale gelen, dijital görüntülerden topografik bilgi elde etmeye yarayan bir tekniktir (Morgan \& Brogan, 2016; Yakar vd., 2015; Şasi \& Yakar, 2018). Özellikle son yıllarda kullanımı artan SFM, yüksek çözünürlüklü veri kümeleri üzerinde çalışmayı mümkün kılan, düşük maliyetli ve kullanıcı dostu bir fotogrametri tekniğidir (Ulvi vd., 2019; Alptekin vd., 2019). SfM ile oluşturulan modelin referanslanarak geleneksel fotogrametrinin de konusunu oluşturan ortofoto, sayısal yüzey modeli ve konum ve yöneltme parametreleri belirlenmiş fotoğrafların oluşturulmasıdır (Yiğit vd., 2020). Bu sayede sıralı bir dizi olarak çekilmiş iki boyutlu (2B) görüntüler kullanılarak 3B yapıların dijital modellerinin oluşturulmasını sağlamaktadır (Sanz-Ablanedo vd., 2018; Alptekin \& Yakar, 2020b).

Bu çalışmada, havadan İHA yardımıyla temin edilen 2 boyutlu resimler ile $3 \mathrm{~B}$ model üretmek için Pix4D yazılımı kullanılmıştır. Pix4D model üretiminde Hareket ile Nesne Oluşturma-Structure From Motion (SFM) yöntemini kullanmaktadır. SFM; son yıllarda kullanımı artan, yüksek çözünürlüğe sahip veri kümelerini üzerinde çalışan, düşük maliyetli fotogrametri tekniğidir (Sarıtürk \& Şeker, 2017; Febro, 2020). SFM tekniği ile bindirmeli ve sıralı olarak çekilen 2B resimlerden objelerin (tarihi eser, bina, arazi, yeryüzü şekilleri vs.) 3B dijital modelinin üretilmektedir.

$\mathrm{Bu}$ çalışmada toplanan verilerin işlenmesi Pix4D yazılımında 132 adet manuel olarak çekilen resim YKN noktalarının yardımıyla dengelenmesi yapılmıştır (Şekil 8). Dengelenen resimlerden yazılımda orta yoğunlukta yaklaşık 43735000 3B nokta verisi üretilmiştir (Şekil 9). Üretilen veriler mesh yapılarak yüzey geçirilmiş ve $3 \mathrm{~B}$ dijital modeli üretilmiştir (Şekil 10). 3B model doğruluğu $1.2 \mathrm{~cm}$ olarak üretilmiştir.

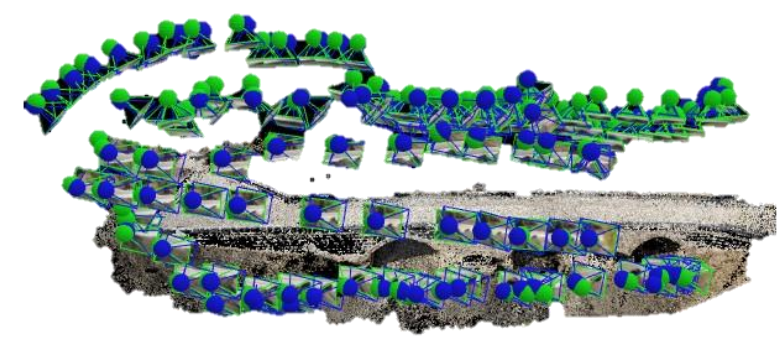

Şekil 8. Resim çekim noktalarının ve bağlama noktalarının görünümü

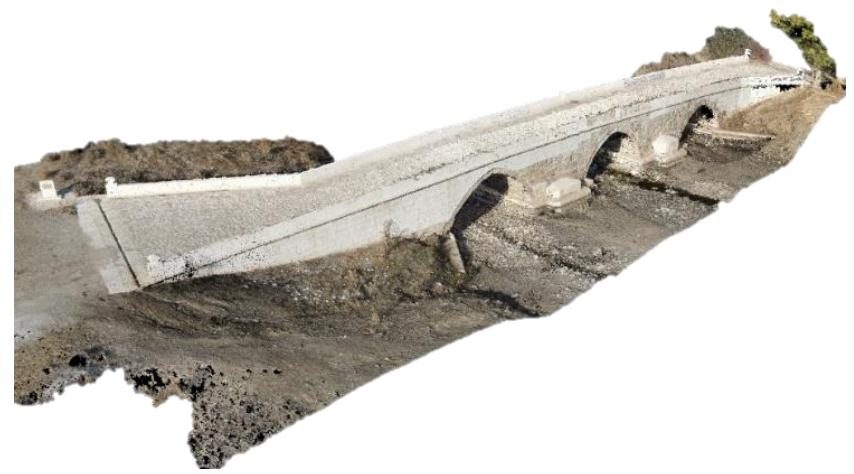

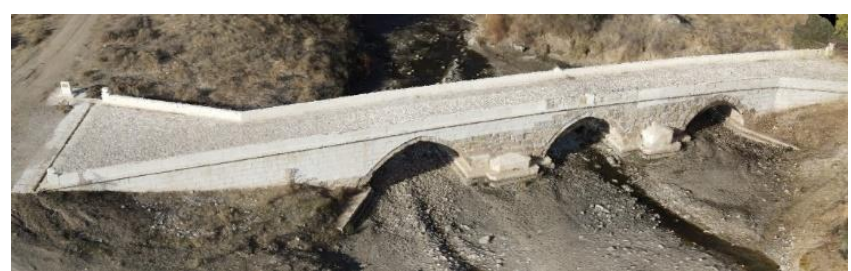

Şekil 10. Mesh yapılmış olarak model görünümü

\section{SONUÇLAR}

Bir toplumun geçmişi, günümüzü ve geleceği ile olan bağlarını güçlendirmenin en iyi yollarından biri tarihi ve kültürel mirasın korunarak yaşatılmasıdır. $\mathrm{Bu}$ nedenle bu mirasa sahip çıkarak durumlarının tespiti, belgelenmesi ve aslına uygun olarak restore edilmesi insanlığın en önemli sorumluluklarından biridir.

Tek yapı ölçeğinden kentsel, arkeolojik ölçeğe kadar mimari mirasın zengin olduğu Türkiye'de tarihi ve kültürel yapıların-alanların korunması için yapılacak restorasyon, rehabilitasyon, yeniden kullanım çalışmalarının hassas yapılması kadar hızlı ve ekonomik olması da çok önemlidir. Çünkü Türkiye'de bir an önce yok olmaya yüz tutmuş pek çok anıtsal yapının, geleneksel-kentsel dokunun, arkeolojik alanların varlığ koruma çalışmalarının kısa bir zamanda yapılmasını gerektirmektedir. $\mathrm{Bu}$ nedenle hassas bir ölçüm elde edilebilen fotogrametrik rölöve tekniği ile $3 \mathrm{~B}$ dijital verilerinin üretilmesi koruma çalışmalarında ayrıca hem zaman açısından hem de maliyet açısından tasarruf da edilecektir. $\mathrm{Bu}$ çalışmada İHA verilerinden yararlanılmıștır. SFM yöntemi kullanılarak fotogrametrik değerlendirme ile $1.2 \mathrm{~cm}$ nokta konum doğruluğunda 3B model üretilmiştir.

\section{KAYNAKÇA}

Aber J, Marzolff I \& Ries J (2010). Small-Format Aerial Photography: Principles, Techniques and Geoscience Applications. Elsevier Science

Ahunbay Z (2004). Tarihi Çevre Koruma ve Restorasyon, 3. Baskı, Yapı Yayın-28, İstanbul.

Alptekin A \& Yakar M (2020a). Mersin Akyar Falezi'nin 3B modeli. Türkiye Lidar Dergisi, 2(1), 5-9.

Alptekin A \& Yakar M (2020b). Heyelan Bölgesinin İha Kullanarak Modellenmesi. Türkiye İnsansız Hava Araçları Dergisi, 2(1), 17-21.

Alptekin A, Çelik M Ö, Doğan Y \& Yakar M (2019). Mapping of a rockfall site with an unmanned aerial vehicle. Mersin Photogrammetry Journal, 1(1), 1216.

Dellaert F, Seitz S M, Thorpe C E \& Thrun S (2000). Structure from motion without correspondence. Proceedings. IEEE Conference on Computer Vision and Pattern Recognition, CVPR 2000 (Cat. No.PR00662), Hilton Head Island, SC, 557-564 Vol. 2, doi:10.1109/CVPR.2000.854916.

Şekil 9. Nokta Bulutu görünümü 
Eisenbeiss $H$ (2008). UAV photogrammetry in plant sciences and geology, In: 6th ARIDA Workshop on "Innovations in 3D Measurement, Modeling and Visualization, Povo (Trento), Italy.

Febro J D. (2020). 3D Documentation of Cultural Heritage Sites Using Drone and Photogrammetry: A Case Study of Philippine UNESCO-Recognized Baroque Churches. International Transaction Journal of Engineering, Management, \& Applied Sciences \& Technologies, 11(8), 1-14.

Furukawa Y \& Hernández C (2013). Multi-View Stereo: A Tutorial. Foundations and Trends $\AA$ in Computer Graphics and Vision, Vol. 9, No. 1-2, 1-148.

Hamal S N G, Sarı B \& Ulvi A (2020). Using of Hybrid Data Acquisition Techniques for Cultural Heritage a Case Study of Pompeiopolis. Türkiye İnsansız Hava Araçları Dergisi, 2(2), 55-60.

Kabadayı A, Kaya Y \& Yiğit A Y (2020). Comparison Of Documentation Cultural Artifacts Using The $3 \mathrm{~d}$ Model In Different Software. Mersin Photogrammetry Journal, 2(2), 51-58.

Kaya Y \& Yiğit A Y (2020). Dijital El Kameraları Kullanılarak Kültürel Mirasın Belgelenmesi. Türkiye Fotogrametri Dergisi, 2(2), 33-38.

Kaya Y, Yiğit A Y, Ulvi A \& Yakar M (2021). Arkeolojik Alanların Dokümantasyonununda Fotogrametrik Tekniklerinin Doğruluklarının Karşılaştırmalı Analizi: Konya Yunuslar Örneği. Harita Dergisi, 165, 57-72.

Morgan J A \& Brogan D J (2016). How to VisualSFM, Department of Civil \& Environmental Engineering Colorado State University Fort Collins, Colorado.

Sanz-Ablanedo E, Chandler J H, Rodríguez-Pérez J R, Ordóñez C. (2018). Accuracy of unmanned aerial vehicle (UAV) and SfM photogrammetry survey as a function of the number and location of ground control points used. Remote Sensing, 10(10), 1606.

Sarıtürk B \& Şeker D Z (2017). Sfm Tekniği ile 3b Obje Modellenmesinde Kullanılan Ticari ve Açık-Kaynak Kodlu Yazılımların Karşılaştırılması. Afyon Kocatepe Üniversitesi Fen ve Mühendislik Bilimleri Dergisi, 17(4), 126-131.
Şasi A \& Yakar M (2018). Photogrammetric modelling of hasbey dar'ülhuffaz (masjid) Using an unmanned aerial vehicle, International Journal of Engineering and Geosciences (IJEG), 3(1), DOI: 10.26833/ijeg.328919

Tanyeli U (1979). Korumanın İşlevi Üzerine Gözlemler, Mimarlık 79/1, 158.

Turner D, Lucieer A \& Watson C (2012). An automated technique for generating georectified mosaics from ultra-high resolution unmanned aerial vehicle (UAV) imagery, based on structure from motion (SfM) point clouds. Remote sensing, 4(5), 13921410.

Ulvi A (2021). Documentation, Three-Dimensional (3D) Modelling and visualization of cultural heritage by using Unmanned Aerial Vehicle (UAV) photogrammetry and terrestrial laser scanners. International Journal of Remote Sensing, 42(6), 1994-2021.

Ulvi A, Yakar M, Yiğit A \& Kaya Y (2019). The Use of Photogrammetric Techniques in Documenting Cultural Heritage: The Example of Aksaray Selime Sultan Tomb. Universal Journal of Engineering Science, 7(3), 64-73.

Ulvi A, Yakar M, Yiğit A Y \& Kaya Y (2020). İHA ve Yersel Fotogrametrik Teknikler Kullanarak Aksaray Kızl Kilise'nin 3 Boyutlu Nokta Bulutu ve Modelinin Üretilmesi. Geomatik Dergisi, 5(1), 22-30.

Yakar M, Orhan O, Ulvi A, Yiğit A Y, Yüzer M M. (2015). Sahip Ata Külliyesi Rölöve Örneği. TMMOB Harita ve Kadastro Mühendisleri Odası, 10.

Yiğit A Y \& Ulvi A (2020). İHA Fotogrametrisi Tekniği Kullanarak 3B Model Oluşturma: Yakutiye Medresesi Örneği. Türkiye Fotogrametri Dergisi, 2(2), 46-54.

Yiğit A Y, Orhan 0 \& Ulvi A (2020). Investigation of The Rainwater Harvesting Potential at The Mersin University, Turkey. Mersin Photogrammetry Journal, 2(2), 64-75. 